\title{
Professor William Kerr Lindsay: September 3, 1920 - February 5, 2008
}

Hugh G Thomson MD MS FRCSC FACS

$\mathrm{P}$ lastic surgery has lost an especially great icon. In recent years, our lives have come to revolve around acronyms and we almost need a dictionary to read most contemporary articles. Fitting then, to ask, what does the acronym WKL stand for?

The 'W' obviously stands for 'what a wonderful winner', or a 'willingness' to share his gentlemanly thoughtfulness with the myriad of past trainees. This wonderful style was unique in that he always basked in the reflection of his students' success and never aspired to personal gain.

The ' $\mathrm{K}$ ' stands for a present-day 'kool' in every respect - in the operating room, at rounds, in professional meetings or just face-to-face. There was never a tremor in his operating hands, even under the greatest stress...now that's 'kool'. 'K' also stands for 'kind', which he preached to, and practiced with his four great children and all others with whom he came in contact. As the Argo's Michael 'Pinball' Clemons stated, "I'm here to support others so they can have success"... that was also Bill's 'kingly' way.

The 'L' definitely stands for 'leader'. Bill was class president while at medical school, president of the Canadian Society of Plastic Surgeons (1964) and American Association of Plastic Surgeons (1971), and Chief of Plastic Surgery at the Hospital for Sick Children, Toronto, Ontario. Add to this his very successful chairmanship of the Division of Plastic Surgery at the University of Toronto (1958 to 1986), President of the 3rd International Congress on Cleft Palate (Toronto, Ontario), honorary leader of the INCO Visiting Professor Symposium, and inspiration for the WK Lindsay Club. As a leader, he received many awards, including the Order of Ontario. He was also a Board of Trustees member of the RS McLaughlin Foundation, which subsidized hundreds of Canadian doctors to train overseas. Bill was also a recipient of this fellowship himself. He was on the Board of the Bickell and the Speech Foundation of Ontario as well as the Lanzhou Burn Centre in Gansu Province, China, and a member of innumerable committees.

'L' also stands for the 'light' side of Bill, which he demonstrated during a frigid American Hand Surgery Society meeting when the Burlington Express train, out of Chicago, lost a wheel, causing a major delay. During this period, with all members on board, Bill donned a train porter's cap and served drinks to all his member friends with a big smile.

After retirement, he spent Wednesday afternoons scrubbed in the operating room at the Hospital for Sick Children, during which time he regaled us with a lifetime of stories and invaluable lessons.

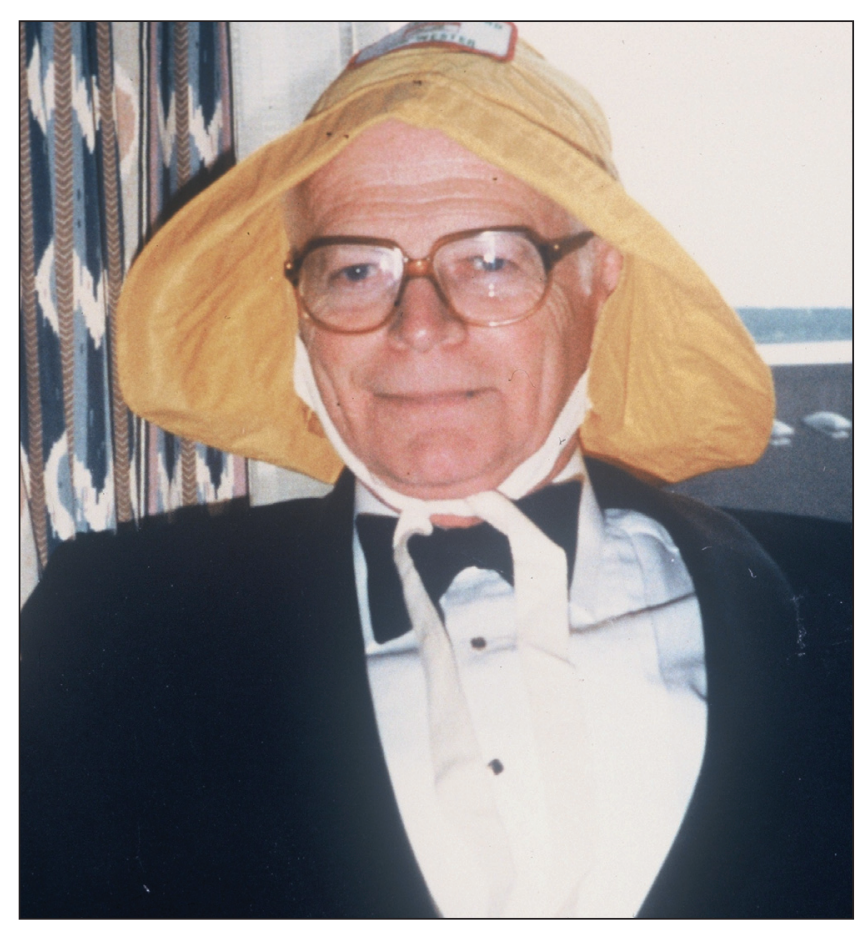

South-western roots

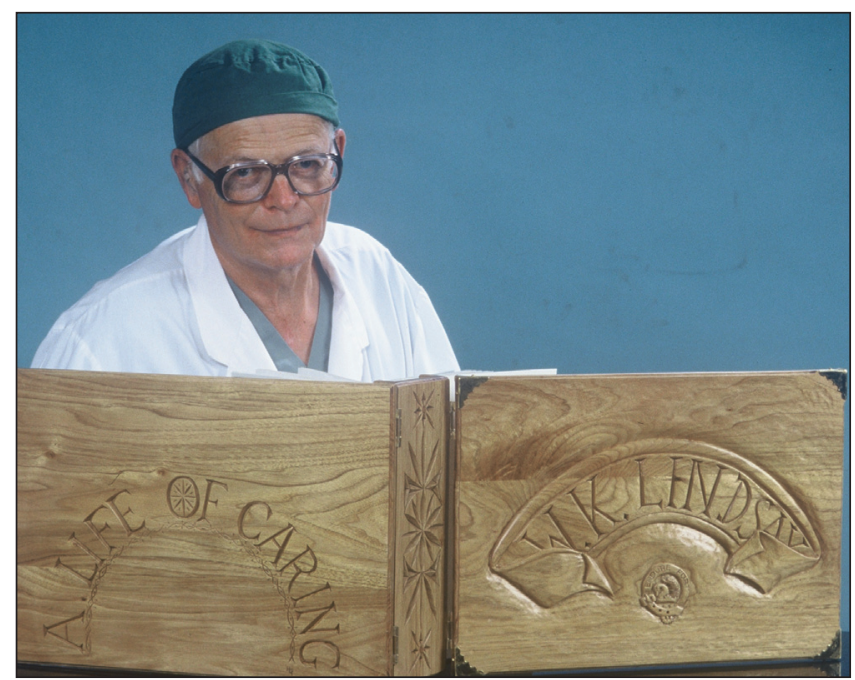

Life of caring 
He demonstrated leadership qualities similar to another famous British Columbian, National Basketball Association point guard Steve Nash, who believed, "It is better to be selfless and pass than to shoot at the net oneself". Bill always led by example, publishing 122 peer-reviewed articles during his program directorship, teaching 128 clinical residents and 25 clinical and 21 research fellows. All of these students experienced the famous Sir Isaac Newton lesson in that they could see so far by standing on the shoulders of a giant, and Bill was that!

He was a great example of the aphorism that behind every successful man stands a strong, loving woman, and Peggy was surely this for 63 years. She provided tremendous all-round support in Bill's later years. Together, they practiced conservation concepts on their Skytop farm in Mono, Ontario and they were active members of their community and church.

Bill has left a valued, indelible imprint on all of us for which we are forever grateful. A truly Aristotelian man, wherein "dignity does not consist in possessing honours, but in deserving them". He embodied the Lindsay family motto of "Endure Fort".

Lanky Bill with an all-discerning eye

Encouraged his students to reach for the sky

They all did this with great élan.

This principle will be with them for their entire life span. 